\title{
Add-on omalizumab in children with severe allergic asthma: a 1-year real life survey
}

\author{
Antoine Deschildre1, Christophe Marguet², Julia Salleron ${ }^{3}$, Isabelle Pin ${ }^{4}$, \\ Jean-Luc Rittié ${ }^{\text {, Jocelyne Derelle }}{ }^{6}$, Rola Abou Taam7\%, Mickael Fayon ${ }^{8}$, \\ Jacques Brouard ${ }^{9}$, Jean Christophe Dubus ${ }^{10}$, Daniel Siret ${ }^{11}$, Laurence Weiss ${ }^{12}$, \\ Guillaume Pouessel ${ }^{13}$, Laurent Beghin ${ }^{14}$ and Jocelyne Just ${ }^{15}$
}

\begin{abstract}
Affiliations: 'Unité de Pneumologie-Allergologie Pédiatrique, Pôle Enfant, Clinique de Pédiatrie Jeanne de Flandre, CHRU de Lille, Université Nord de France, Lille, ${ }^{2}$ Pediatric Respiratory Disease and Allergy Unit, University Charles Nicolle Hospital, EA3830 GHRV, Rouen University, Rouen, ${ }^{3}$ Département de Biostatistiques, CHRU de Lille, Université Nord de France, Lille, ${ }^{4}$ Pédiatrie, Pôle Couple Enfants, CHU de Grenoble, INSERM U823, Institut Albert Bonniot, Université Joseph Fourier, Grenoble, ${ }^{5}$ Allergologie-Pneumologie, Hôpital des Enfants, CHU Purpan, Toulouse, 'Service de Pédiatrie 1, Hôpital d'enfants de Brabois, CHU Nancy, Vandoeuvre-Lés-Nancy, ${ }^{7}$ Service de Pneumologie et Allergologie Pédiatriques, AP-HP, Hôpital Necker Enfants Malades, Université Paris Descartes-Paris 5, Paris, ${ }^{8} \mathrm{CHU}$ de Bordeaux, Département de Pédiatrie, Centre d'Investigation Clinique (CIC 0005), 33000 Bordeaux, ${ }^{9} \mathrm{CHU}$ de Caen, Dept of Pediatrics, Research Unit EA 4655 U2RM, Caen, ${ }^{10}$ Unité de Pneumologie et Médecine Infantile, CNRS, URMITE 6236, CHU TimoneEnfants, Aix-Marseille Université, Marseille, ${ }^{11}$ Service de Pédiatrie, $\mathrm{CH}$ de Saint-Nazaire, Saint-Nazaire, ${ }^{12}$ Pôle Médico-Chirurgical de Pédiatrie, CHU de Hautepierre, Strasbourg, ${ }^{13}$ Service de Pédiatrie, $\mathrm{CH}$ de Roubaix, Roubaix, ${ }^{14}$ Centre d'Investigation Clinique-9301, CHRU Lille, U995 Inserm, Université Nord de France, Lille, and ${ }^{15}$ Centre de l'Asthme et des Allergies, Hôpital d'Enfants Armand-Trousseau-26, Paris, France.
\end{abstract}

Correspondence: A. Deschildre, Unité de Pneumologie-allergologie Pédiatrique, Clinique de Pédiatrie Jeanne de Flandre, CHRU, 59037 Lille cedex, France. E-mail: antoine.deschildreachru-lille.fr

ABSTRACT Omalizumab has been shown to reduce exacerbation rates in moderate to severe allergic asthma. Our aim was to evaluate omalizumab efficacy and safety in a real-life setting in severe asthmatic children.

104 children (aged 6-18 years), followed up in paediatric pulmonary tertiary care centres, were included at the beginning of omalizumab treatment. Asthma control levels, exacerbations, inhaled corticosteroid dose, lung function and adverse events were evaluated over 1 year.

Children were characterised by allergic sensitisation to three or more allergens (66\%), high IgE levels (mean $1125 \mathrm{kU} \cdot \mathrm{L}^{-1}$ ), high rate of exacerbations (4.4 per year) and healthcare use during the previous year, and high inhaled corticosteroid dose (mean $703 \mu \mathrm{g}$ equivalent fluticasone per day). Asthma control levels defined as good, partial or poor, improved from $0 \%, 18 \%$ and $82 \%$ at entry to $53 \%, 30 \%$ and $17 \%$ at week 20 , and to $67 \%, 25 \%$ and $8 \%$ at week 52 , respectively $(\mathrm{p}<0.0001)$. Exacerbation and hospitalisation rates dropped by $72 \%$ and $88.5 \%$, respectively. At 12 months, forced expiratory volume in $1 \mathrm{~s}$ improved by $4.9 \%$ $(\mathrm{p}=0.023)$, and inhaled corticosteroid dose decreased by $30 \%(\mathrm{p}<0.001)$. Six patients stopped omalizumab for related significant adverse events.

Omalizumab improved asthma control in children with severe allergic asthma and was generally well tolerated. The observed benefit was greater than that reported in clinical trials.

@ERSpublications

Omalizumab improves asthma control in children with severe allergic asthma and is generally well tolerated http://ow.ly/oLoBp 


\section{Introduction}

The management of severe asthma in children remains a challenge, with its prevalence being estimated at $5 \%$ of the asthmatic population [1]. The term "problematic severe asthma" has been recently preferred to describe these school-aged children who have poorly controlled asthma despite maintenance therapy with $\geqslant 400 \mu \mathrm{g}$ of fluticasone per day or equivalent of inhaled corticosteroids (ICSs) plus inhaled long-acting $\beta$-agonist (LABA) or leukotriene receptor antagonist or theophylline [2]. Those children are characterised at various degrees by daily symptoms, severe or frequent exacerbations, high rates of healthcare utilisation, persistent lung function alteration and altered quality of life. Problematic severe asthma is therefore a costly disease in childhood despite its fairly low frequency. Omalizumab is a recent and expensive treatment designed as an add-on therapy in difficult-to-treat patients with allergic asthma. Children included in clinical trials have been part of a wide age group including mainly adults in the first clinical trial (age range 12-79 years) [3], and then of specific paediatric trials [4-8]. These studies have shown a significant decrease in exacerbations and healthcare use, and an improvement in quality of life, but nonetheless a modest effect on symptoms and lung function tests (LFTs). The French Health Authority has limited the utilisation of omalizumab to allergic children with uncontrolled persistent asthma and/or severe exacerbations, severe airway obstruction evaluated by LFTs when aged $>12$ years, despite being administered high doses of ICS or oral corticosteroids in association with at least LABA. In France, omalizumab has been available since 2006 for children aged $>12$ years and with total $\mathrm{IgE} \leqslant 700 \mathrm{kU} \cdot \mathrm{L}^{-1}$ and since 2009 for those aged $>6$ years and with total $\operatorname{IgE} \leqslant 1500 \mathrm{kU} \cdot \mathrm{L}^{-1}$. A few real-life studies have been conducted in adults $[9,10]$. The latter have not only confirmed but also extended previous drug efficacy and safety observed in randomised trials. Conversely, knowledge on omalizumab utilisation and safety has remained limited in childhood [11, 12]. This was marked in adolescents (12-18 years) who were diluted in the large primary study [3]. Moreover, the effect of omalizumab on disease control has not yet been assessed as an efficacy outcome [4-7].

This 1-year observational study reports the real-life efficacy and safety of add-on treatment with omalizumab in a large group of children with allergic severe asthma. The primary objective was to evaluate the effect of add-on omalizumab on asthma control, as mentioned in step 5 of the Global Initiative for Asthma (GINA) guidelines [13]. We also assessed other outcomes of efficacy (exacerbation rate, healthcare utilisation, ICS sparing effect and change in lung function), as well as safety.

\section{Material and methods \\ Design}

The study was a 1-year real-life multicentre survey conducted in 12 paediatric pulmonology and allergy tertiary care centres (fig. 1).

\section{Subjects}

All patients with confirmed allergic severe asthma for whom omalizumab treatment was initiated between January 2006 and June 2009, and who were aged $<18$ years were included in the study [14]. They had received long term follow-up ( $>12$ months in the tertiary care centre). This allowed characterisation of their asthma phenotype and evaluation of treatment efficacy and compliance. The survey was approved by the Nord Pas de Calais Human Protection Committee for Clinical Research as well as the National Committee for Freedom of Information (Commission Nationale de l'Informatique et des Libertés).

\section{Methods}

Baseline characteristics were collected from medical files: demographic data, asthma history (age at diagnosis of asthma, hospitalisation for asthma ever and intensive care unit (ICU) admission ever), asthma severity over the past year assessed using rate of exacerbations requiring systemic corticosteroids and/or healthcare utilisation (emergency department (ED) visits and hospitalisation), allergic sensitisation assessed by skin prick tests, specific and total IgE levels, and comorbidities (allergic rhinitis, atopic dermatitis, food allergy, and overweight determined by body mass index $>97$ th percentile for age and sex).

This article has supplementary material available from www.erj.ersjournals.com

Received: Sept 202012 | Accepted after revision: Feb 142013 | First published online: March 212013

Support statement: This study was supported by a grant from Novartis France and the French Paediatric Pulmonology and Allergy Society (SP2A).

Conflict of interest: Disclosures can be found alongside the online version of this article at www.erj.ersjournals.com 


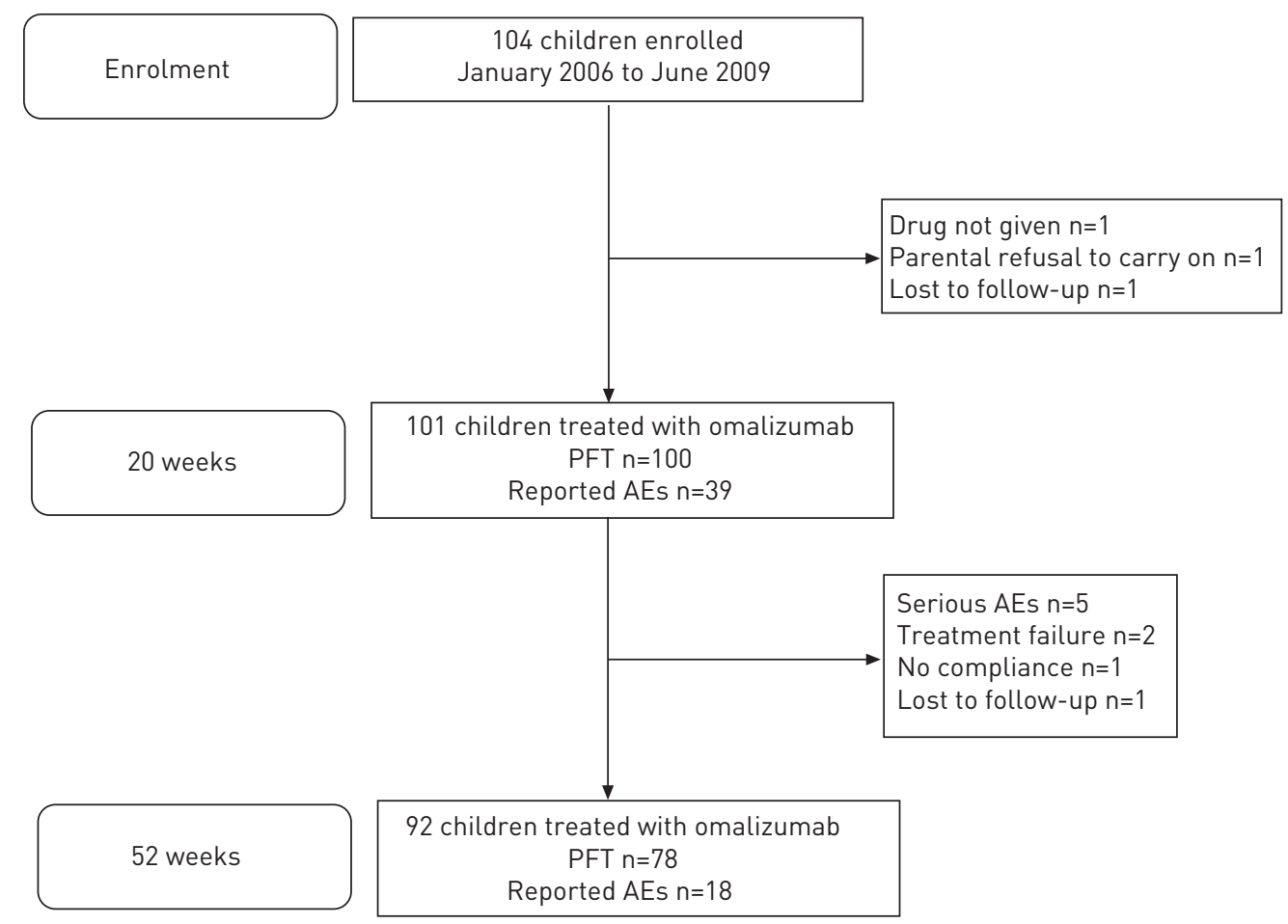

FIGURE 1 Flow chart showing the course of study. PFT: pulmonary function test; AE: adverse event.

\section{Assessment of efficacy and safety}

Data were collected and recorded on a standardised file at the time of the first administration (V0), at $20 \pm 4$ weeks (V1) and at $52 \pm 4$ weeks (V2). Level of asthma control was assessed over the 4 weeks preceding each visit, and classified as poor, partial or good according to the GINA 3 levels: controlled, partly controlled and uncontrolled asthma [13]. Exacerbations were quantified separately and only those needing systemic steroid bursts $\geqslant 3$ days were retained in the evaluation, as highlighted in previous trials [4-7]. Healthcare utilisation was estimated by the number of ED visits or hospitalisation or admission to ICU for asthma. LFTs comprised a flow-volume curve pre- and post-inhaled $\beta 2$-agonists, and were routinely performed in each centre. Forced expiratory volume in $1 \mathrm{~s}$ (FEV1) and forced expiratory flow at 25-75\% of the forced vital capacity (FVC) (FEF25-75\%) were expressed as \% predicted values, and the FEV1/FVC ratio as a percentage. Data on maintenance therapy were collected at each visit and ICS doses were standardised as fluticasone equivalent dose per day (fluticasone propionate $\mu \mathrm{g} \cdot \mathrm{day}^{-1}$ ), according to French guidelines. At each visit, any significant adverse events (AEs) were reported to evaluate the safety of the drug. They were described in a narrative form and then classified in significant or serious AEs, as required by the European Medicines Agency. Significant AE resulted in any intervention, e.g. treatment discontinuation, and serious AE resulted in hospitalisation, any life-threatening events or incapacity.

\section{Analyses}

The primary outcome criterion of omalizumab responsiveness was to achieve good asthma control over the year of treatment. We defined good asthma control according to the GINA criteria of controlled asthma (daytime symptoms: twice or less per week; limitation of activities: none; nocturnal symptoms/awakening: none; need for reliever/rescue treatment: twice or less per week, and normal FEV1 according to the GINA guidelines [13]). The secondary criteria were the reduction in severe exacerbation rate and healthcare use in comparison with that observed during the previous year, the reduction in ICS dose, and the lung function improvement over the year of treatment. Safety was analysed separately.

\section{Statistics}

Data are presented as n (\%) for qualitative variables and as mean (95\% confidence interval) for quantitative variables. Comparisons between V0, V1 and V2 were performed by a MacNemar test for qualitative variables and by a t-test for paired samples for quantitative variables.

In our population, bivariate analysis was performed to examine potential factors that may affect the response to omalizumab at V1 and V2. The relationship between age ( $<12$ or $\geqslant 12$ years), FEV1/FVC $(<0.8$ or $\geqslant 0.8)$, 
number of exacerbation in the previous year $(<3$ or $\geqslant 3)$, sensitisations $(<3$ or $\geqslant 3)$, allergic comorbidities (present or absent), IgE level ( $\leqslant 700$ or $>700 \mathrm{kU} \cdot \mathrm{L}^{-1}$ ), dosing regimen (every 2 or 4 weeks) and the response to omalizumab were investigated by Chi-squared tests. To determine the relation between a good response to omalizumab and IgE level, a Mann-Whitney test was used. The correlations between continuous variables were measured by Pearson's correlation coefficient. We also analysed all the outcomes in the subgroup of patients with IgE level $>700 \mathrm{kUI} \cdot \mathrm{L}^{-1}$. A p-value $\leqslant 0.05$ was considered significant. All analyses were performed using SAS software version 9.2 (SAS Institute Inc., Cary, NC, USA).

\section{Results}

\section{Descriptive data}

104 children were included, all fulfilling the criteria of severe asthma (table 1). 44\% of them had been hospitalised during the previous year, with 20 children requiring more than one admission, leading to 87 stays, eight of which were in the ICU. Six (5.8\%) children required continuous oral corticosteroid therapy. This atopic population was characterised by: 1) very high IgE levels, with a value above the threshold of $700 \mathrm{kIU} \cdot \mathrm{L}^{-1}$ in $57(55 \%)$ children, IgE levels between $1500-3000 \mathrm{kU} \cdot \mathrm{L}^{-1}$ in 20 children and $>3000 \mathrm{kIU} \cdot \mathrm{L}^{-1}$

\begin{tabular}{|c|c|}
\hline Age years & $11.9(11.3-12.5)$ \\
\hline Age $<12$ years & $47(45)$ \\
\hline Sex male & $60(58)$ \\
\hline Overweight & 20 (19) \\
\hline \multicolumn{2}{|l|}{ History of asthma } \\
\hline Duration of asthma years & $9.1(8.3-9.9)$ \\
\hline Exercise induced asthma & $89(86)$ \\
\hline$\geqslant 1$ ED attendance ever & $70(68)$ \\
\hline Ever hospitalised & $77(74)$ \\
\hline Ever hospitalised in ICU & $17(16.5)$ \\
\hline \multicolumn{2}{|l|}{ Allergy and allergic comorbidities } \\
\hline Allergic rhinitis & 88 (84.5) \\
\hline Atopic dermatitis & $35(34)$ \\
\hline Food allergy & $36(35)$ \\
\hline Total IgE levels $\mathrm{kU} \cdot \mathrm{L}^{-1}$ & $1125(934-1315)$ \\
\hline Sensitisation to aeroallergens & $101(97)$ \\
\hline$>2$ sensitisations & $69(66)$ \\
\hline \multicolumn{2}{|l|}{ Asthma-related events in the previous year } \\
\hline Exacerbation rate & $4.4(3.7-5.2)$ \\
\hline$>2$ oral steroid courses & $68(65.5)$ \\
\hline ED visit & $70(67)$ \\
\hline Hospitalisation & $46(44)$ \\
\hline$>1$ hospitalisation & 20 (19) \\
\hline Hospitalisation in ICU & $8(7.7)$ \\
\hline \multicolumn{2}{|l|}{ Asthma medication at baseline } \\
\hline ICS & $104(100)$ \\
\hline Dose of ICS fluticasone equivalent $\mu \mathrm{g} \cdot$ day $^{-1}$ & 703 (642-764) \\
\hline Association with LABA & $98(94)$ \\
\hline$>2$ long-term controller medication & 93 (89.5) \\
\hline Daily SABA & $48(46)$ \\
\hline Maintenance oral corticosteroids & $6(5.5)$ \\
\hline \multicolumn{2}{|l|}{ Lung function tests } \\
\hline FEV $1 \%$ pred & $88(83.8-92.2)$ \\
\hline $\mathrm{FEV}_{1} / \mathrm{FVC} \%$ & $75.8(72.5-79.1)$ \\
\hline FEF25-75\% \% pred & $65.1(58.8-71.4)$ \\
\hline \multicolumn{2}{|l|}{ Asthma control } \\
\hline Poor & $85(82)$ \\
\hline Partial & $19(18)$ \\
\hline Good & $0(0)$ \\
\hline
\end{tabular}

Data are presented as mean (95\% CI) or $\mathrm{n}(\%)$. BMI: body mass index; ED: emergency department; ICU: intensive care unit; ICS: inhaled corticosteroid; LABA: long-acting $\beta_{2}$-agonists; SABA: short-acting $\beta_{2^{-}}$ agonists; FEV1: forced expiratory volume in $1 \mathrm{~s} ; \%$ pred: \% predicted; FVC: forced vital capacity; FEF25-75\%: forced expiratory flow at $25-75 \%$ of FVC. ${ }^{\#}$ : $n=104 ;{ }^{\circ}$ : BMI $>97$ th percentile. 


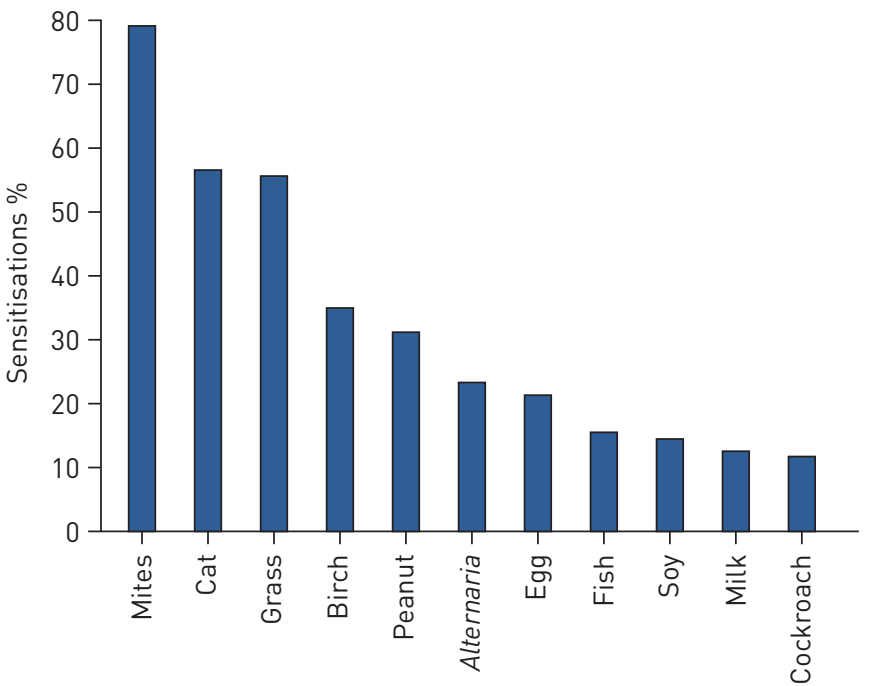

FIGURE 2 Allergen sensitisations detected at baseline in the overall population $(\mathrm{n}=104)$. Food allergies, Alternaria and cockroach sensitisations were overrepresented in these severe asthmatic children.

in seven children; 16 of these 27 children with the highest IgE levels were aged $<12$ years; 2) polysensitisation: $66 \%$ had allergic sensitisation to at least three allergens; 3 ) a high frequency of food allergies (35\%); and 4) a high frequency of allergic rhinitis (85\%) (table 1 and fig. 2). Lung function tests revealed airway obstruction with $\mathrm{FEV}_{1}<80 \%$ pred in $36 \%$, or $\mathrm{FEF}_{2} 5-75 \%<60 \%$ pred in $51 \%$, $\mathrm{FEV} 1 / \mathrm{FVC}$ $<0.8$ in $53 \%$ and $<0.7$ in $26 \%$ of children.

The outcomes were available in 101 patients at V1 and 92 patients at V2 (fig. 1). At V1, treatment was discontinued in eight children by the physician. One more patient was lost to follow-up between V1 and V2.

\section{Omalizumab dosage}

Omalizumab was administered as required by the dosing table available at the time of the initial prescription, establishing doses for up to IgE level $<700 \mathrm{kU} \cdot \mathrm{L}^{-1}$ according to weight. Thus, the children with IgE levels above this threshold received the maximum recommended dose of $375 \mathrm{mg}$ every 2 weeks. $68 \%$ of children were administered omalizumab every 2 weeks and the remaining $32 \%$ received the treatment every 4 weeks. Due to the high IgE levels encountered in this population, there were two injection sites for $76 \%$ of children and the number rose to three sites for $6 \%$ of patients. Overall, $58 \%$ required local anaesthetic by lidocaine/prolicaine application at the sites of injections.

\section{Asthma control}

Control of asthma clearly improved over the year of treatment (fig. 3). Asthma control levels were good in $0 \%$, partial in $18 \%$ and poor in $82 \%$ of the population at treatment initiation and improved to $53 \%, 30 \%$ and $17 \%$ at week 20 , and to $67 \%, 25 \%$ and $8 \%$ at week 52 , respectively $(\mathrm{p}<0.0001) .20(20 \%)$ patients with partially controlled $(n=16)$ or uncontrolled $(n=4)$ asthma at V1 became in good control at V2. Conversely, six children improved at V1, and then lost control between V1 and V2. In addition, 11 (10.5\%) children with poor asthma control at V0 moved to partial control at V1 and V2. Thus, only $14 \%$ of the children did not improve over the year. Mean baseline IgE levels were not different between patients with good control and without control (partial or poor control) at $\mathrm{V} 1$ or $\mathrm{V} 2$ (V1: 1214 (385-1797) $\mathrm{kU} \cdot \mathrm{L}^{-1}$ versus 1040 (380-1445) $\mathrm{kU} \cdot \mathrm{L}^{-1}$, respectively, $\mathrm{p}=0.32 ; \mathrm{V} 2$ : 1173 (365-1714) $\mathrm{kU} \cdot \mathrm{L}^{-1}$ versus $891(276-1061) \mathrm{kU} \cdot \mathrm{L}^{-1}$, respectively, $\mathrm{p}=0.21$ ).

\section{Exacerbations}

A significant decrease in the number of exacerbations was observed under treatment, when compared with the previous year (fig. 4). The mean rate of severe exacerbations decreased from 4.4 (3.7-5.2) per patient during the previous year to $1.25(0.55-1.95)$ during the year of treatment $(\mathrm{p}<0.0001)$. This represented a reduction of $72 \%$ over the year. A low rate of exacerbation $(0.66(0.33-0.99)$ per patient) was early observed over the period V0-V1, and was maintained at $0.57(0.23-0.93)$ per patient over the period V1-V2. In addition, the percentage of children requiring hospitalisation decreased from $44 \%$ in the past year to $6.7 \%$ $(\mathrm{n}=7,10$ admissions), with none necessitating a stay in ICU during the year on treatment $(\mathrm{p}<0.001)$. Hospital admissions were reduced by $88.5 \%$. 
FIGURE 3 Asthma control levels at baseline $(\mathrm{n}=104)$, at $20 \pm 4$ weeks $(\mathrm{n}=101)$ and at $52 \pm 4$ weeks $(n=92)$ after the initiation of addon omalizumab treatment.

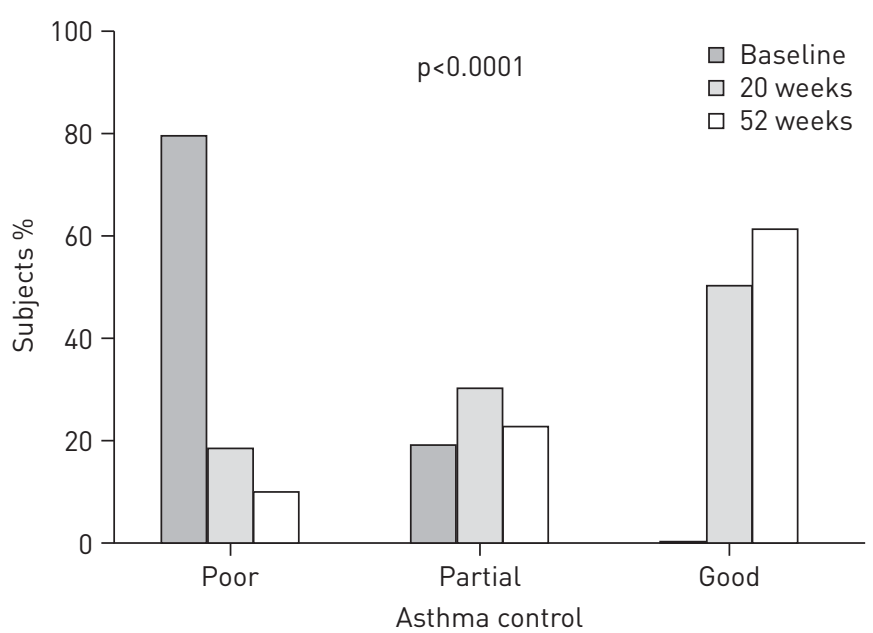

\section{Lung function tests}

FEV1 was available in 78 and FEF25-75\% in 64 children over the year of follow-up (fig. 5). The mean improvement of lung function assessed at V2 was $4.9 \%$ pred $(95 \%$ CI $0.69-9.19 ; \mathrm{p}=0.023)$ and $9.5 \%$ pred (95\% CI 3.7-15.2; $\mathrm{p}=0.002)$ for FEV1 and $\mathrm{FEF} 25-75 \%$, respectively.

\section{Inhaled steroid sparing effect}

Over the year on treatment, the ICS sparing effect was $-212(-284--140) \mu \mathrm{g}$, equivalent to a $30 \%$ reduction in ICS dose (fig. 6). The mean administered dose of FP or equivalent was $703(642-764) \mu \mathrm{g}$ at V0, 592 $(528-656) \mu \mathrm{g}$ at $\mathrm{V} 1$ and $481(412-551) \mu \mathrm{g}$ at V2 $(\mathrm{p}<0.0001) .46 .7 \%$ of patients achieved $\geqslant 50 \%$ reduction in the administered dose, and only 5.4\% maintained unchanged ICS doses between V0 and V2. Oral corticosteroids were withdrawn in all six children with this maintenance therapy at baseline.

\section{Effect modifiers of the response to omalizumab}

The only significant factor associated with a good response to omalizumab was age. Children aged $<12$ years were less frequently controlled at V2 than older children $(53.5 \%$ versus $76 \% ; \mathrm{p}=0.02)$ and exacerbations were more frequent under treatment $(1.85(0.33-3.38)$ versus $0.76(0.45-1.08) ; \mathrm{p}=0.049)$ (tables S1 and S2). Neither of the characteristics detailed above, allergic comorbidities (allergic rhinitis, atopic dermatitis and food allergy) and rate of allergenic sensitisations, were predictive of good control at V1 or V2. We also analysed the administration frequency (every 2 weeks versus every 4 weeks) and we did not find any difference in all outcomes (table S1 and S3).

Next we repeated the analysis in the subgroup of children with high IgE levels $\left(>700 \mathrm{kU} \cdot \mathrm{L}^{-1}\right)$. We did not find any relation between IgE level and all the outcomes (table S4).

FIGURE 4 Change in exacerbation rates over a period of 52 weeks with add-on omalizumab treatment in children with uncontrolled severe allergic asthma. Data are presented as mean (95\% confidence interval).

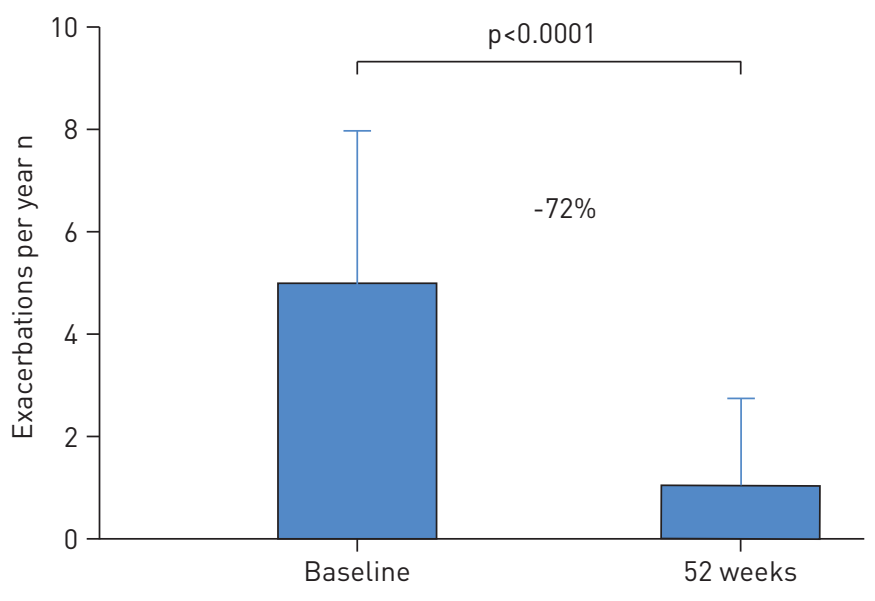




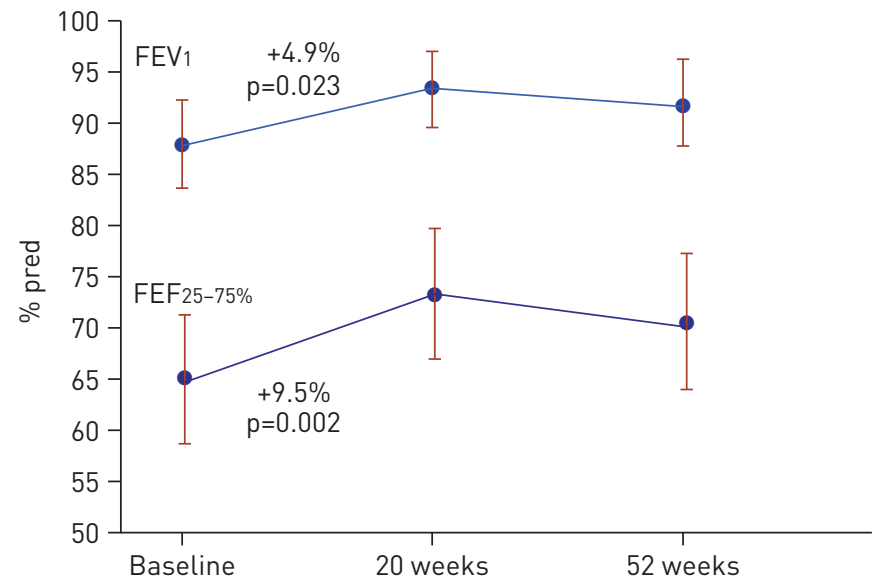

FIGURE 5 Changes in mean $(95 \%$ confidence interval) pre-bronchodilator forced expiratory volume in $1 \mathrm{~s}$ ( $\mathrm{FEV} 1)$ and forced expiratory flow at $25-75 \%$ of forced vital capacity (FEF25-75\%) from baseline during the treatment with omalizumab.

Safety

Overall, at least one AE was reported in 47 children (fig. 1). The most frequent AEs were pain at injection site $(n=23)$, which led to discontinuation in one patient, and local reaction in 10 others. Symptoms such as asthenia after injections $(n=6)$, headache $(n=3)$, abdominal pain $(n=3)$ and vagal malaise $(n=3)$ were also reported. Serious AEs due to omalizumab according to physician's assessment, which allowed a precise characterisation (five at V1 and one at V2), resulted in treatment discontinuation in six patients, as follows: extended urticaria $(n=1)$, anaphylaxis $(n=1)$, and systemic reactions associated with abdominal and muscular pain, fatigue and headache $(n=4)$. Omalizumab was successfully reinitiated under medical supervision in two of these patients. The last declared event was a case of anaphylaxis linked to exotic fruit allergy, and was unrelated to omalizumab.

\section{Discussion}

We report an observational survey of 104 atopic children and adolescents with severe allergic asthma, who benefited from omalizumab treatment as an add-on therapy to high level maintenance treatment. All children in this series had received long-term follow-up in tertiary care centres, which allowed them to have a precise characterisation of their asthma, and to target the associated co-factors with poor asthma control, such as compliance or environmental exposures. The interest of observational studies is to provide complete real-life data, which might differ from that obtained in clinical trials (table S5). Our survey showed a greater improvement in asthma control, a greater reduction in exacerbation rates and healthcare utilisation and a greater steroid-sparing effect than that reported in efficacy trials. Notably, the children studied appeared to be more severely affected, less controlled and more atopic than those in the previous clinical trials, suggesting a specific clinical profile targeted by omalizumab. These results in childhood are in agreement with those recently observed in other observational studies in adults and adolescents with severe allergic persistent asthma $[9,10]$. The primary outcome point of this survey was the number of children who achieved good control level (according to the GINA criteria [13]), thus providing new data of clinical relevance. The clinical trials have definitely shown omalizumab efficacy on exacerbation rates. By contrast,

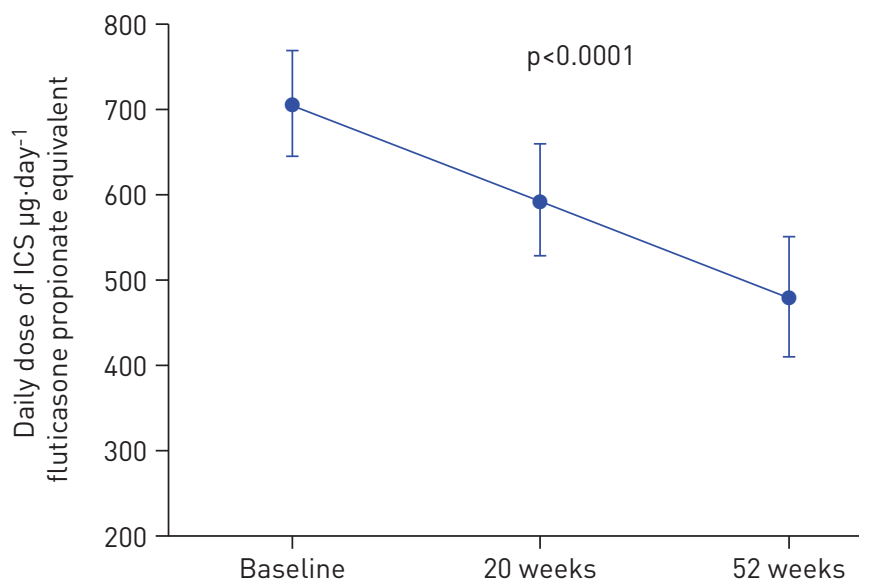

FIGURE 6 Changes in daily inhaled corticosteroid (ICS) dose $\left(\mu \mathrm{g} \cdot \mathrm{day}^{-1}\right.$ fluticasone propionate-equivalent) from baseline during the treatment with omalizumab. Data are presented as mean $(95 \%$ confidence interval). 
this effect was less marked in the control of symptoms [4-7]. In this survey, control was obtained for half of the children during the first 20 weeks of drug administration. In addition, prolonged treatment of up to 1 year enabled two-thirds of these children to achieve good control. These data suggest that the recommended mean recognised time interval of 4 months for drug response evaluation has to be considered on a case-by-case basis. Taking into account those who moved from poor to partial control, only $14 \%$ of the children did not improve. That means that one in six should be considered as nonresponders. A reduction in night symptoms and use on demand of bronchodilators was observed by MiLGROM et al. [6], but not by LANIER et al [5]. In less severe asthmatic children, BusSE et al. [4] reported a decrease of 25\% of symptom score, comprising day and night symptoms, school absenteeism and activity interference, over 2 weeks. These authors observed a significant gain of asthma control, assessed by the Asthma Control Test, only in the 6-11-year-old age range. In our survey, the response was also observed in this age group, but was less pronounced. Young age should not delay anti-IgE treatment when required.

The other main finding was a $72 \%$ reduction in the rate of severe exacerbations, with only a few participants needing hospitalisation and none being admitted to the ICU when receiving omalizumab. A reduction in exacerbation rate was the most significant effect attributed to omalizumab and was estimated to lead to a $43-45 \%$ reduction in a recent meta-analysis [11]. Our results reinforced the previous $43-50 \%$ reduction reported in children with moderate or severe asthma $[5,7]$. In addition, the effect on exacerbations was obtained during the first months of treatment, in accordance with the 28- and 16-week studies by MiLGrom et al. [6] and BRODLIE et al. [8], respectively. In contrast, KuLus et al. [7] observed the highest reduction of exacerbation during the final 6 months in their 1-year trial.

One of the additional benefits observed in this survey of severe allergic asthmatics was the corticosteroidsparing effect. The drop in oral steroid bursts was an expected consequence of the dramatic reduction in exacerbations. Furthermore, all six children who had previously required daily oral steroid treatment were able to stop taking them, in accordance with a recent report [8]. It was possible to decrease the ICS dose in almost all patients. This contrasts with the modest $4 \%$ reduction in ICS dosing reported in children with similar high ICS doses, but less severe asthma [5]. Conversely, Milgrom et al. [6] reported a 100\% decrease in the median ICS dose in young patients exposed to a dose five times lower than in this and other series [5]. Although limited, these current data support the fact that the step down was not related to the ICS dose administered at the onset of omalizumab. BUSSE et al. [4] also reported a significant difference in the ICS dose of $109 \mu \mathrm{g} \cdot$ day $^{-1}$ budesonide-equivalents between the omalizumab and placebo groups, which was greater in those children exposed and sensitised to cockroaches and those with a more severe asthma.

Lastly, both large (FEV1) and small (FEF25-75\%) airway functional parameters improved over the year of treatment, which was not observed in previous trials $[4,6]$. Although the increase was small and may be not clinically relevant, it did provide a positive outcome, as a decline in lung function has been described in severe asthmatic children followed up for many years [15]. The persistence of this positive impact on lung function over time may illustrate a modifier effect on long-term disease progression in patients with severe asthma unlike that of inhaled corticosteroids drugs.

This improvement in asthma control was observed despite the fact that nearly half of patients might be considered as receiving a suboptimal dose of omazilumab, as the European dosing table at the time of study was limited to an IgE level of $<700 \mathrm{kU} \cdot \mathrm{L}^{-1}$. Nonetheless, response to treatment depends on the reduction of free IgE levels [16], which is not related to measured IgE levels and cannot be routinely evaluated. Finally, response to treatment was not modified by administration frequency. This supports the proposal to decrease the frequency of the injections every 4 weeks when the total dose is $\leqslant 600 \mathrm{mg}$ every 4 weeks.

We cannot definitely exclude that improvement may be linked to the subcutaneous mode of omalizumab administration, which improved compliance in comparison with that of inhaled drugs. However, our population was comprised of children with poorly controlled asthma, followed up over many years in tertiary care centres where compliance was routinely assessed [2, 14]. This suggests that most of them belonged to a true therapy-resistant asthma profile. Compared with the children included in US paediatric trials [4-7], the patients included in our study had more severe asthma and with higher rates of exacerbation needing oral steroids (4.4 per year versus $1.9-2.7$ per year), hospitalisations (74\% versus $18-52 \%)$ and requiring high rates of healthcare utilisation. In fact, European omalizumab approbation was more restrictive than US approbation, limiting administration in poorly controlled severe asthma treated with high doses of ICS or oral steroids in association with at least a LABA. As is often the case in severe childhood asthma, the associated alteration of lung function remained moderate, but with a wide range of variation $[15,17]$. Half of the children, however, displayed a diminished FEF25-75\%, which appeared to be the most sensitive marker of functional alteration in severe asthma $[1,18]$. 
These children featured a peculiar severe atopic phenotype. Total IgE concentration was more than twofold that previously reported in omalizumab trials $[5,6]$, two-thirds of the children were polysensitised, onethird had food allergy, and rhinitis comorbidity was nearly constant. An elevated production of total $\operatorname{IgE}$ was demonstrated to be a marker of asthma severity in children [19] and was related to greater healthcare utilisation, altered lung function and airway hyperresponsiveness [20,21]. In contrast, such a severe allergic profile has not yet been clearly individualised as a risk group in problematic severe asthma either in previous cohorts $[15,17]$ or in recent guidelines [2]. A polysensitisation to three or more allergens has nevertheless been associated with severe $[22,23]$ or uncontrolled asthma [24]. This is in accordance with recent findings, which defined a specific phenotype of severe asthma in children with multiple sensitisations not only to inhaled but also to food allergens [25]. Food allergies have been determined as a risk factor of lifethreatening asthma exacerbations [26], and also appear to be involved in cases of difficult asthma. Lastly, a sensitisation to Alternaria, an allergen previously associated with severe asthma [27], was also overrepresented within this cohort. The rate was eightfold higher than the $2.8 \%$ recently determined in a large French study [28].

The proportion of systemic reactions or general symptoms was comparable to that recently detailed by Milgrom et al. [29] in a safety review, where no difference in the number or categories of AEs between the drug and control groups was revealed in the previous trials. Pain or local reaction after injection was not only the most frequent but also the most expected phenomenon, given the viscosity of the product at the time of the survey. These AEs are currently diminishing with the recent modification of the drug composition. Compared with this safety review [29], we report fewer cases of urticaria, headaches and only one related anaphylaxis. Six patients presented with serious adverse effects and discontinued treatment administration. According to the benefit response to omalizumab, two patients were successfully retreated at hospital and no adverse effect occurred. This suggests that the benefit/risk balance should be reassessed in children with therapy resistant asthma.

In conclusion, omalizumab is an effective and safe add-on therapy in uncontrolled severe asthmatic and allergic children. Those characterised by high IgE production, polysensitisations and/or food allergy were revealed to form a subpopulation of true highly allergic severe asthma, and responded well to omalizumab.

\section{Acknowledgements}

We are grateful to Anne Sardet (Service de Pédiatrie, Lens, France) for her contribution and Phillippe Fauquembergue, Céline Clairet (Centre d'Investigations Cliniques Pédiatriques, Lille University Hospital, Lille, France) and Carole Langlois (Biostatistics Department, Lille University Hospital, Lille, France) for data collection and management. We are grateful to Nikki Sabourin-Gibbs (Rouen University Hospital, Rouen, France) for her assistance with writing and reviewing the manuscript in English.

\section{References}

Lang A, Carlsen KH, Haaland G, et al. Severe asthma in childhood: assessed in 10 year olds in a birth cohort study. Allergy 2008; 63: 1054-1060.

2 Hedlin G, Bush A, Lødrup Carlsen K, et al. Problematic severe asthma in children, not one problem but many: a GA2LEN initiative. Eur Respir J 2010; 36: 196-201.

3 Humbert M, Beasley R, Ayres J, et al. Benefits of omalizumab as add-on therapy in patients with severe persistent asthma who are inadequately controlled despite best available therapy (GINA 2002 step 4 treatment): INNOVATE. Allergy 2005; 60: 309-316.

4 Busse WW, Morgan WJ, Gergen PJ, et al. Randomized trial of omalizumab (anti-IgE) for asthma in inner-city children. N Engl J Med 2011; 364: 1005-1015.

5 Lanier B, Bridges T, Kulus M, et al. Omalizumab for the treatment of exacerbations in children with inadequately controlled allergic (IgE-mediated) asthma. J Allergy Clin Immunol 2009; 124: 1210-1216.

6 Milgrom H, Berger W, Nayak A, et al. Treatment of childhood asthma with anti-immunoglobulin E antibody (omalizumab). Pediatrics 2001; 108: E36.

7 Kulus M, Hebert J, Garcia E, et al. Omalizumab in children with inadequately controlled severe allergic (IgEmediated) asthma. Curr Med Res Opin 2010; 26: 1285-1293.

8 Brodlie M, McKean MC, Moss S, et al. The oral corticosteroid-sparing effect of omalizumab in children with severe asthma. Arch Dis Child 2012; 97: 604-609.

9 Brusselle G, Michils A, Louis R, et al. "Real-life" effectiveness of omalizumab in patients with severe persistent allergic asthma: The PERSIST study. Respir Med 2009; 103: 1633-1642.

10 Cazzola M, Camiciottoli G, Bonavia M, et al. Italian real-life experience of omalizumab. Respir Med 2010; 104: $1410-1416$.

11 Rodrigo GJ, Neffen H, Castro-Rodriguez JA. Efficacy and safety of subcutaneous omalizumab vs placebo as add-on therapy to corticosteroids for children and adults with asthma: a systematic review. Chest 2011; 139: 28-35.

12 Berger W, Gupta N, McAlary M, et al. Evaluation of long-term safety of the anti-IgE antibody, omalizumab, in children with allergic asthma. Ann Allergy Asthma Immunol 2003; 91: 182-188.

13 Global Initiative for Asthma (GINA). Global Strategy for Asthma Management and Prevention, Global Initiative for Asthma (GINA) 2012. www.ginasthma.org/ documents/4 Date last accessed: September 10, 2013.

14 Lødrup Carlsen KC, Hedlin G, Bush A, et al. PSACI (Problematic Severe Asthma in Childhood Initiative) group. Assessment of problematic severe asthma in children. Eur Respir J 2011; 37: 432-440. 
15 Chipps BE, Szefler SJ, Simons FE, et al. Demographic and clinical characteristics of children and adolescents with severe or difficult-to-treat asthma. J Allergy Clin Immunol 2007; 119: 1156-1163.

16 Lowe PJ, Tannenbaum S, Gautier A, et al. Relationship between omalizumab pharmacokinetics, IgE pharmacodynamics and symptoms in patients with severe persistent allergic (IgE-mediated) asthma. $\mathrm{Br} J \mathrm{Clin}$ Pharmacol 2009; 68: 61-76.

17 Lang A, Mowinckel P, Sachs-Olsen C, et al. Asthma severity in childhood, untangling clinical phenotypes. Pediatr Allergy Immunol 2010; 21: 945-953.

18 Illi S, von Mutius E, Lau S, et al. Perennial allergen sensitisation early in life and chronic asthma in children: a birth cohort study. Lancet 2006; 368: 763-770.

19 Borish L, Chipps B, Deniz Y, et al. Total serum IgE levels in a large cohort of patients with severe or difficult-totreat asthma. Ann Allergy Asthma Immunol 2005; 95: 247-253.

20 Sears MR, Burrows B, Flannery EM, et al. Relation between airway responsiveness and serum IgE in children with asthma and in apparently normal children. N Engl J Med 1991; 325: 1067-1071.

21 Naqvi M, Choudhry S, Tsai HJ, et al. Association between IgE levels and asthma severity among African American, Mexican, and Puerto Rican patients with asthma. J Allergy Clin Immunol 2007; 120: 137-143.

22 Fitzpatrick AM, Gaston BM, Erzurum SC, et al. Features of severe asthma in school-age children: Atopy and increased exhaled nitric oxide. J Allergy Clin Immunol 2006; 118: 1218-1225.

23 Carroll WD, Lenney W, Child F, et al. Asthma severity and atopy: how clear is the relationship? Arch Dis Child 2006; 91: 405-409.

24 de Blic J, Boucot I, Pribil C, et al. Control of asthma in children: still unacceptable? A French cross-sectional study. Respir Med 2009; 103: 1383-1391.

25 Just J, Gouvis-Echraghi R, Rouve S, et al. Two novel severe asthma phenotypes identified during childhood using a clustering approach. Eur Respir J 2012; 40: 55-60.

26 Roberts G, Patel N, Levi-Schaffer F, et al. Food allergy as a risk factor for life-threatening asthma in childhood: a case-controlled study. J Allergy Clin Immunol 2003; 112: 168-174.

27 Neukirch C, Henry C, Leynaert B, et al. Is sensitization to Alternaria alternata a risk factor for severe asthma? A population-based study. J Allergy Clin Immunol 1999; 103: 709-711.

28 Randriamanantany ZA, Annesi-Maesano I, Moreau D, et al. Alternaria sensitization and allergic rhinitis with or without asthma in the French Six Cities study. Allergy 2010; 65: 368-375.

29 Milgrom H, Fowler-Taylor A, Vidaurre CF, et al. Safety and tolerability of omalizumab in children with allergic (IgE-mediated) asthma. Curr Med Res Opin 2011; 27: 163-169. 